\title{
Antioxidants with Multivitamin and Mineral Supplementation Attenuates Chemotherapy or Radiotherapy-induced Oxidative Stress in Cancer Patients
}

\author{
Ravikant Yashwantrao Patil ${ }^{1, *}$, Harinath Nivrutti More ${ }^{2}$ \\ ${ }^{1}$ Department of Pharmacology, D.S.T.S Mandal's College of Pharmacy, Solapur, Maharashtra, INDIA. \\ ${ }^{2}$ Department of Pharmaceutical Chemistry, Bharati Vidyapeeth's College of Pharmacy, Morewadi, Kolhapur, Maharashtra, INDIA.
}

\begin{abstract}
Aim: The present study was planned to evaluate the combined effects of antioxidant multivitamin and minerals (AMM) in reducing cancer and cancer therapy-induced oxidative stress. In addition cell viability of human malignant melanoma and normal mouse fibroblast cell lines after treatment with different concentrations of $A M M$ and methotrexate were also estimated. Methods: Amongst the 120 cancer patients recruited for the study, 60 patients each were treated with radiotherapy and chemotherapy. In both radiotherapy and chemotherapy, 30 patients each were supplemented with AMM for 30 days. Thirty healthy human volunteers were recruited for comparison. On day 31, blood samples were collected for estimation of oxidative stress markers (MDA and nitrite), endogenous (SOD and GPx) and exogenous (Vitamin C and Vitamin E) antioxidants and essential trace elements (zinc, copper and selenium). In addition, cell viability of human malignant melanoma and normal mouse fibroblast cell lines were estimated after treatment with different concentrations of AMM and methotrexate. Results: Supplementation of AMM during cancer therapy minimized the burden of free reactive radicals and restored the endogenous and exogenous antioxidants and essential trace element levels. In addition, AMM has no cytotoxic effect on normal mouse fibroblast cell lines. But AMM imparts suppression of cell proliferation in human malignant melanoma. Conclusion: Supplementation of antioxidants with multivitamin and mineral during cancer therapy is found to be beneficial as they minimize the burden of free reactive radicals and restores the endogenous and exogenous antioxidants and essential trace element levels.
\end{abstract}

Key words: Cancer, Antioxidants, Multivitamin, Chemotherapy, Radiotherapy.

\section{INTRODUCTION}

Extensive scientific studies have shown that oxidative stress is involved in several acute and chronic diseases including cancer. ${ }^{1,2}$ Elevated levels of Reactive Oxygen Species (ROS) causes overproduction of malondialdehyde (MDA), a final product of polyunsaturated fatty acids peroxidation in the cells. Hence, MDA is commonly considered as one of the key markers of oxidative stress and antioxidant status in cancerous patients. ${ }^{3}$ Increased levels of ROS and cell damage is linked with the pathogenesis of cancer. ${ }^{1}$

Antioxidants are substances that may protect tissues and organs from the damage caused by free radicals. Antioxidants neutralize free radicals by donating one of their own electrons and ending the electron "stealing" reaction. This helps to prevent ROS mediated cell and tissue damage. ${ }^{4}$ A delicate balance between oxidants and antioxidants is required for the normal functioning of living systems.
Submission Date: 02-10-2019; Revision Date: 22-11-2019; Accepted Date: 08-01-2020

DOI: 10.5530/ijper.54.2.55 Correspondence: Ravikant Yashwantrao Patil,

Department of Pharmacology, D.S.T.S Mandal's College of Pharmacy, Solapur-413004, Maharashtra, INDIA.

Phone: +91 9422647764

E-mail: rypatilsir@gmail.com

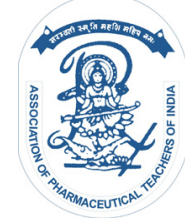

www.ijper.org 
Imbalance between the production of free radicals and their elimination by antioxidant defence mechanism induces loss of cell membrane function and its integrity. In addition, increased oxidative stress leads to DNA damage which promotes genomic instability and cell proliferation. This facilitates tumour initiation and tumour promotion. Hence, oxidative stress is a key component in the carcinogenesis process. ${ }^{5,6}$

On the other hand, radiation and some chemotherapeutic agents used in cancer treatment generate ROS. High ROS level in the body diminishes cellular antioxidant capacity and cause damage and necrosis of malignant cells. Hence, radiation and chemotherapeutic agents also produce toxic effect on normal cells due to the diminished cellular antioxidant capacity in cancer patients. So, antioxidant supplements are widely used by cancer patients in order to prevent the toxic side effects of cancer treatment. ${ }^{1-5}$

In addition to antioxidants, essential trace elements also play a vital role in many biochemical enzymatic reactions and have been examined critically as a potential key factor in various human diseases including cancers. Zinc and selenium play an anti-carcinogenic role through structural stabilization of DNA, RNA and ribosome. Zinc and selenium have a protective effect against freeradical injury. Previous studies reported that there is a strong association between decreased concentration of serum selenium and zinc with various types of cancers such as ovarian, testicular, cervical, bladder and renal cancer. ${ }^{7-9}$ Decreased amounts of the essential trace elements especially selenium and zinc were observed in post-therapy of cancer. ${ }^{10}$

It is well documented that cancer patients often suffer from Vitamin deficiencies, especially of folic acid, Vitamin $\mathrm{C}$ and pyridoxine. Cancer therapy reduces serum levels of antioxidant Vitamins due to lipid peroxidation and thus produces an elevated level of oxidative stress. Therefore, supplementation of certain antioxidants and nutrients can help to enhance the health status of patients undergoing continuous regime of chemotherapy. ${ }^{4}$

In light of the above facts, present study was planned to evaluate the combined effects of antioxidants with multivitamin and minerals (AMM) in reducing cancer therapy-induced oxidative stress in cancer patients. In addition, cell viability of A-375 human malignant melanoma cell line and the L-929 normal mouse fibroblast cell line after treatment with different concentrations of AMM and methotrexate were also estimated.

\section{MATERIALS AND METHODS}

\section{Effect of AMM in cancer therapy-induced oxidative stress}

Total 120 patients clinically diagnosed with cancer of any type and free from severe infections, major operations, hepatic or respiratory diseases, other chronic inflammatory conditions, trauma, GI disorder, diabetes and non-alcoholic and non-smokers were included in the study. Out of 120 patients, 60 patients underwent radiotherapy and 60 patients were on chemotherapy in Shri Siddheshwar Cancer Hospital and Research Centre, Solapur, Maharashtra, India. For comparison of data 30 healthy volunteers were recruited. The study protocol was approved by the institutional ethical committee (IEC/COPS/01) and written informed consent was obtained from the subjects.

Subjects were divided into five groups, namely group I: healthy volunteers; group II: patients on radiotherapy without AMM supplementation; group III: patients on radiotherapy supplemented with AMM; group IV: patients on chemotherapy without AMM supplementation; and group V: patients on chemotherapy supplemented with AMM.

AMM supplementation involved the daily administration for one month of an AMM tablet containing Vitamin-A acetate (500 IU), Vitamin-B1 (10 mg), Vitamin-B2 (10 mg), Vitamin-B6 (3 mg), Vitamin-B12 $(5 \mu \mathrm{g})$, Vitamin-C (100 mg), Vitamin-D3 (500 IU), Vitamin-E acetate (25 IU), niacinamide (50 mg), folic acid $(1 \mathrm{mg})$, calcium pantothenate $(12.5 \mathrm{mg})$, chromic chloride $(65 \mu \mathrm{g})$, cupric oxide $(2.5 \mathrm{mg})$, manganese chloride $(1.4 \mathrm{mg})$, sodium selenate $(60 \mu \mathrm{g})$ and zinc oxide (15 mg).

After one month $24 \mathrm{hr}$ post last dose of AMM supplementation, blood samples were collected into the heparinised bulb for serum collection and non-heparinised sterile bulb for plasma collection. Plasma and serum were separated from respective bulbs by centrifugation at $3000 \mathrm{rpm}$ for $10-15 \mathrm{~min}$ at room temperature. Then all samples were stored at $4^{\circ} \mathrm{C}$ before the analysis. Serum samples were used to estimate total lipid peroxide, ${ }^{11}$ nitric oxide (as nitrite) ${ }^{12}$ total antioxidants, ${ }^{13}$ glutathione peroxidase, ${ }^{14}$ Vitamin $\mathrm{E},{ }^{15}$ zinc, $^{16}$ copper $^{16}$ and selenium and plasma sample were used to estimate superoxide dismutase ${ }^{17}$ and Vitamin C. ${ }^{18}$

\section{Effect of AMM on in vitro proliferation}

The cell viability study was done by using 3- (4, 5dimethylthiazol $-2 \quad-y l) \quad-2,5 \quad$-diphenyl tetrazolium bromide (MTT) reduction method. 
A-375 human malignant melanoma cell line and L-929 normal mouse fibroblast cell line were cultured in DMEM medium supplemented with 10\% heat-inactivated fetal calf serum (FBS) and 1\% antibiotic- antimycotic 100X solution. The seeding of the cells was done at an approximate density of $5 \times 103$ cells per well in a flat bottom 96-well microplate and incubated overnight at $37^{\circ} \mathrm{C}$ in $95 \%$ humidity and $5 \% \mathrm{CO}_{2}$. The cell lines were treated with different concentrations $(62.5 \mu \mathrm{g} /$ $\mathrm{ml}, 125 \mu \mathrm{g} / \mathrm{ml}, 250 \mu \mathrm{g} / \mathrm{ml}, 500 \mu \mathrm{g} / \mathrm{ml}$ and $1000 \mu \mathrm{g} /$ $\mathrm{ml}$ ) of AMM and methotrexate and incubated for $24 \mathrm{hr}$. Then incubated cells were washed twice with phosphate buffer and $20 \mu \mathrm{l}$ of MTT staining solution $(5 \mathrm{mg} / \mathrm{ml}$ in phosphate buffer) were added to each well and incubated at $37^{\circ} \mathrm{C}$ for $4 \mathrm{hr}$. Then amount of formazan synthesized after reduction of MT'T by mitochondrial enzyme of viable cells was dissolved by adding $100 \mu \mathrm{l}$ di-methyl sulfoxide at each well. The absorbance was read spectrophotometrically using micro plate reader at $570 \mathrm{~nm}$ wave length. The cell viability was expressed as percentage cell survived after treatment using the formula:

$$
\text { Cell viability }(\%)=\frac{\text { Mean OD of test compound }}{\text { Mean OD of Negative control }} \times 100
$$

Inhibiting cells $(\%)=100$ - Surviving cells

\section{Statistical analysis}

Data were expressed as means \pm SDs. Statistical analysis were carried out by One-way analysis of variance (ANOVA) followed by Tukey post hoc test. $P$ values $<0.05$ were taken to indicate statistically significant differences.

\section{RESULTS}

\section{Effect of AMM in cancer therapy-induced oxidative stress}

\section{Total lipid peroxide}

The extent of serum lipid peroxidation estimated as malondialdehyde (MDA) was elevated to a significant $(P<0.001)$ level in the patients undergone radiotherapy $(1368.41 \pm 668.79 \mathrm{nM} / \mathrm{dl})$ or chemotherapy $(1509.28 \pm$ $182.03 \mathrm{nM} / \mathrm{dl})$ compared to that in the control group $(510.47 \pm 87.21 \mathrm{nM} / \mathrm{dl})$. Supplementation of AMM to the patients undergoing radiotherapy (1142.46 \pm $90.77 \mathrm{nM} / \mathrm{dl})$ or chemotherapy $(90.77 \mathrm{nM} / \mathrm{dl})$ reduced the extent of lipid peroxidation significantly $(P<0.05)$ compared to that in the control group. The percentage decrease in MDA levels in both these groups were $16.51 \%$ and $20.43 \%$, respectively (Figure 1).

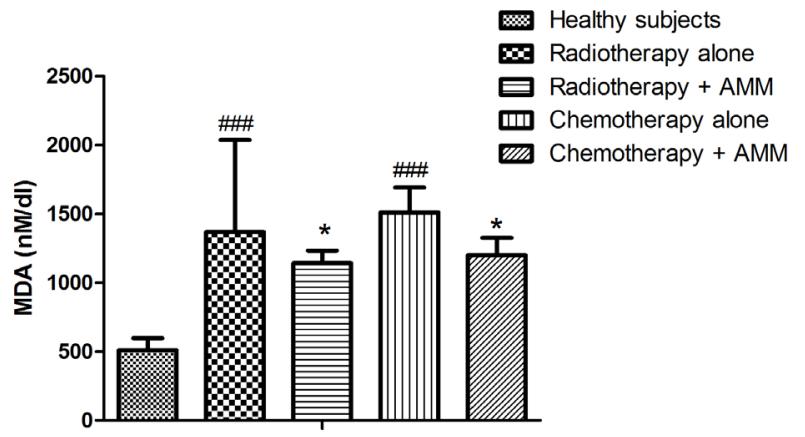

Figure 1: Effect of AMM supplementation on serum MDA levels in cancer patients receiving radiotherapy or chemotherapy.

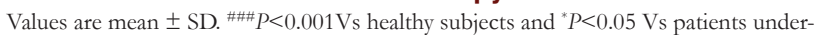
gone radiotherapy or chemotherapy alone.

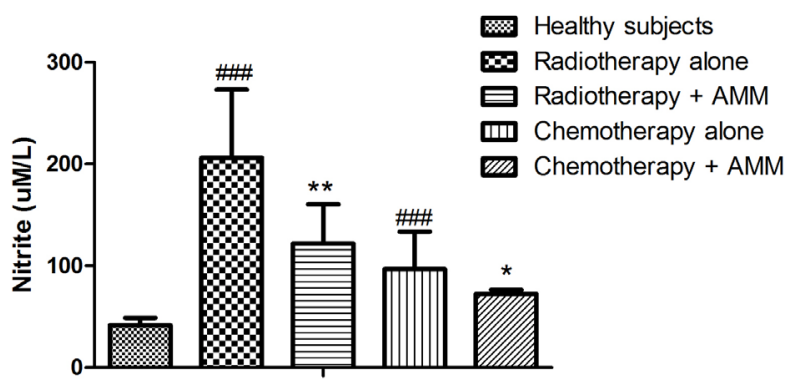

Figure 2: Effect of AMM supplementation on serum nitrite levels in cancer patients receiving radiotherapy or chemotherapy.

Values are mean $\pm \mathrm{SD} .{ }^{\# \#} P<0.001 \mathrm{Vs}$ healthy subjects, ${ }^{*} P<0.05$ Vs patients undergone chemotherapy alone and " $P<0.01$ Vs patients undergone radiotherapy alone.

\section{Nitric Oxide}

The extent of serum nitric oxide estimated as nitrite was found to be significantly $(P<0.001)$ increased in the patients undergone radiotherapy $(206.14 \pm 67.07 \mu \mathrm{M} / \mathrm{L})$ or chemotherapy $(96.69 \pm 36.85 \mu \mathrm{M} / \mathrm{L})$ compared to that in the control group $(41.59 \pm 7.28 \mu \mathrm{M} / \mathrm{L})$. Treatment with $\mathrm{AMM}$ to the patients undergoing radiotherapy $(121.96 \pm 38.53)$ or chemotherapy $(72.27 \pm 4.09 \mu \mathrm{M} / \mathrm{L})$ significantly $(P<0.01$ and $P<0.05$, respectively) reduced nitric oxide level when compared with patients undergone radiotherapy or chemotherapy without AMM treatment. The percentage decrease in nitric oxide levels in both these groups were $40.83 \%$ and $25.25 \%$, respectively (Figure 2).

\section{Total Antioxidant}

Effect of AMM on serum total antioxidant levels in radiotherapy or chemotherapy undergone cancer patients are depicted in Figure 3. Compared to the control group $(5.32 \pm 0.28 \mu \mathrm{M} / \mathrm{L})$ a significant $(P<0.001$ and $P<0.01$, respectively) depletion of total 


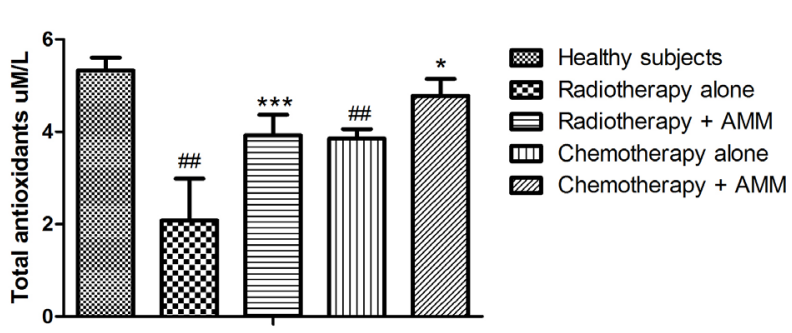

Figure 3: Effect of AMM supplementation on serum total antioxidant levels in cancer patients receiving radiotherapy or chemotherapy.

Values are mean \pm SD. ${ }^{\#} P<0.01$ and ${ }^{\# \#} P<0.001$ Vs healthy subjects, ${ }^{~} P<0.05 \mathrm{Vs}$ patients undergone chemotherapy alone and ${ }^{* * *} P<0.01$ Vs patients undergone radiotherapy alone.

antioxidant levels were observed in patients undergone radiotherapy $(2.08 \pm 0.90 \mu \mathrm{M} / \mathrm{L})$ or chemotherapy $(3.85 \pm 0.21 \mu \mathrm{M} / \mathrm{L})$. Supplementation of AMM to the cancer patients during radiotherapy (3.92 \pm 0.45 $\mu \mathrm{M} / \mathrm{L}, P<0.001))$ or chemotherapy $(4.78 \pm 0.36 \mu \mathrm{M} / \mathrm{L}$, $P<0.05)$ ) restored the total antioxidant levels towards healthy control group subjects.

\section{Enzymatic antioxidants}

The levels of SOD were significantly $(P<0.01)$ decreased in the cancer patients undergoing radiotherapy or chemotherapy compared to that in the control group $(6.41 \pm 0.74 \mathrm{U} / \mathrm{ml})$. The SOD levels in the cancer patients undergoing radiotherapy or chemotherapy were found to be $3.89 \pm 0.39 \mathrm{U} / \mathrm{ml}$ and $4.19 \pm 0.35 \mathrm{U} / \mathrm{ml}$, these values are $39.31 \%$ and $34.63 \%$ less than the healthy subjects, respectively. The SOD levels in cancer patients undergoing radiotherapy or chemotherapy were well restored (18-20\%) by supplementation of AMM during cancer therapy. The values of SOD in these groups were found to be $4.61 \pm 0.58$ and $5.01 \pm 0.59$, respectively and these were found to be statistically significant $(P<0.05)$ compared to non-AMM treated groups (Table 1$)$.
Another estimated enzymatic antioxidant, glutathione peroxidase was also found to be significantly $(P<0.01)$ decreased in cancer patients receiving radiotherapy or chemotherapy compared to that in the control group. In control group, the level of glutathione peroxidase was found to be $678.26 \pm 104.18$ and this was depleted by $40.33 \%$ and $28.60 \%$ in radiotherapy or chemotherapy underwent cancer patients, respectively. Supplementation of $A M M$ to the radiotherapy undergoing cancer patients significantly $(P<0.01)$ restored the glutathione peroxidase level by $26.46 \%$ when compared to the cancer patients not treated with AMM. Supplementation of AMM to the chemotherapy undergoing cancer patients was also restored towards the normal by $4.64 \%$ when compared to the cancer patients not treated with AMM but the values were not statistically significant (Table 1).

\section{Non-enzymatic antioxidants}

Compared to control group the plasma concentration of Vitamin $C$ and Vitamin E were significantly $(P<0.001)$ decreased in cancer patients receiving radiotherapy or chemotherapy. These non-enzymatic antioxidants levels were well restored in cancer patients receiving radiotherapy or chemotherapy supplemented with AMM. Supplementation of AMM significantly $(P<0.001)$ restored the depleted concentration of Vitamin $C$ in cancer patients receiving radiotherapy or chemotherapy by $262.5 \%$ and $75.0 \%$, respectively when compared to the AMM non-treated cancer patients receiving radiotherapy or chemotherapy.

Whereas, supplementation of AMM also restored the depleted concentration of Vitamin $\mathrm{E}$ in cancer patients receiving radiotherapy or chemotherapy by $33.33 \%$ $(P<0.05)$ and $5.43 \%$, respectively when compared to the AMM non-treated cancer patients receiving radiotherapy or chemotherapy. Effect of AMM supplementation on non-enzymatic antioxidants in cancer patients receiving radiotherapy or chemotherapy is shown in Table 1.

\begin{tabular}{|c|c|c|c|c|}
\hline \multicolumn{6}{|c|}{ Table 1: Effect of AMM supplementation on enzymatic and non-enzymatic antioxidants levels in cancer } \\
patients. \\
\hline Group & $\begin{array}{c}\text { SOD } \\
(\mathbf{U} / \mathbf{m l})\end{array}$ & $\begin{array}{c}\text { GPx } \\
(\mathbf{m g} / \mathbf{g m} \text { of } \mathrm{Hb})\end{array}$ & Vitamin C (mg/100ml) & Vitamin E (mg/100ml) \\
\hline Healthy subjects & $6.41 \pm 0.74$ & $678.26 \pm 104.18$ & $1.08 \pm 0.16$ & $1.02 \pm 0.05$ \\
\hline Radiotherapy alone & $3.89 \pm 0.39^{\mathrm{b}}$ & $404.71 \pm 48.73^{\mathrm{b}}$ & $0.16 \pm 0.16^{\mathrm{c}}$ & $0.57 \pm 0.21^{\mathrm{c}}$ \\
\hline Radiotherapy + AMM & $4.61 \pm 0.58^{\mathrm{d}}$ & $511.82 \pm 47.79^{\mathrm{e}}$ & $0.58 \pm 0.14^{\mathrm{f}}$ & $00.76 \pm 00.11^{\mathrm{d}}$ \\
\hline Chemotherapy alone & $4.19 \pm 0.35^{\mathrm{b}}$ & $484.21 \pm 21.42^{\mathrm{b}}$ & $0.48 \pm 0.11^{\mathrm{c}}$ & $0.92 \pm 0.14^{\mathrm{c}}$ \\
\hline Chemotherapy + AMM & $5.01 \pm 0.59^{\mathrm{g}}$ & $506.72 \pm 60.23$ & $0.84 \pm 0.11^{\mathrm{i}}$ & $0.97 \pm 0.05$ \\
\hline
\end{tabular}

Values expressed as mean \pm SD. ${ }^{b} P<0.01$ and ${ }^{c} P<0.001$ V healthy subjects, ${ }^{d} P<0.05,{ }^{e} P<0.01$ and ${ }^{f} P<0.001$ Vs patients undergone radiotherapy alone and ${ }^{9} P<0.05$ and i $P<0.001$ Vs patients undergone chemotherapy alone. 


\begin{tabular}{|c|c|c|c|}
\hline \multicolumn{2}{|c|}{ Table 2: Effect of AMM supplementation on trace elements in levels in cancer patients. } \\
\hline Group & $\begin{array}{c}\text { Selenium } \\
(\mathbf{m g} / \mathbf{m l})\end{array}$ & $\begin{array}{c}\text { Copper } \\
(\boldsymbol{\mu} \mathbf{g} / \mathbf{d l})\end{array}$ & $\begin{array}{c}\text { Zinc } \\
(\boldsymbol{\mu} \mathbf{g} / \mathbf{d l})\end{array}$ \\
\hline Healthy subjects & $0.15 \pm 0.04$ & $111.38 \pm 11.07$ & $86.56 \pm 4.22$ \\
\hline Radiotherapy alone & $0.11 \pm 0.03$ & $134.04 \pm 16.12$ & $71.25 \pm 6.28$ \\
\hline Radiotherapy + AMM & $0.14 \pm 0.02^{\mathrm{b}}$ & $126.59 \pm 3.70$ & $80.68 \pm 4.57$ \\
\hline Chemotherapy alone & $0.10 \pm 0.01$ & $139.83 \pm 15.00$ & $74.08 \pm 3.52$ \\
\hline Chemotherapy + AMM & $0.13 \pm 0.02^{\mathrm{e}}$ & $128.25 \pm 9.39$ & $79.88 \pm 4.00$ \\
\hline
\end{tabular}

Values expressed as mean \pm SD. ${ }^{b} P<0.01$ Vs patients undergone radiotherapy alone and ${ }^{e} P<0.01$ Vs patients undergone chemotherapy alone.

\section{Trace elements}

Table 2 shows the effect of AMM supplementation on trace elements in cancer patients undergoing radiotherapy or chemotherapy. Compared to the control group, concentration of selenium and zinc was decreased and concentration of copper was increased in both radiotherapy and chemotherapy receiving cancer patients. Supplementation of AMM to the radiotherapy or chemotherapy receiving cancer patients restored the concentration of trace elements towards normal. It was observed that supplementation of AMM to the radiotherapy or chemotherapy receiving cancer patients increased the concentration of selenium and zinc by $27-30 \%(P<0.01)$ and $7-13 \%$, respectively, when compared to the radiotherapy or chemotherapy receiving non-AMM treated cancer patients. Interestingly, supplementation of AMM to the radiotherapy or chemotherapy receiving cancer patients increased the concentration of copper by $5-8 \%$ when compared to the radiotherapy or chemotherapy receiving non-AMM treated cancer patients.

\section{Effect of AMM on in vitro proliferation}

Threatment with methotrexate showed dose dependent cytotoxic effect in both A-375 human malignant melanoma cells and L-929 normal mouse fibroblast cells. Where as treatment with AMM to the cell lines showed cytotoxic effect in A-375 human malignant melanoma cells even at lower concentration but it was not suppressed the proliferation of L-929 normal mouse fibroblast cells (Figure 4). Thse results indicates that AMM protect the normal mouse fibroblast cells and act as cytotoxic in human malignant melanoma cells.

\section{DISCUSSION}

Present study showed that supplementation of AMM well protected the cancer patients from radiotherapy or chemotherapy-induced oxidative stress. Moreover, AMM also attenuated cytotoxic effect in L-929 normal mouse fibroblast cells and imparted suppression of cell

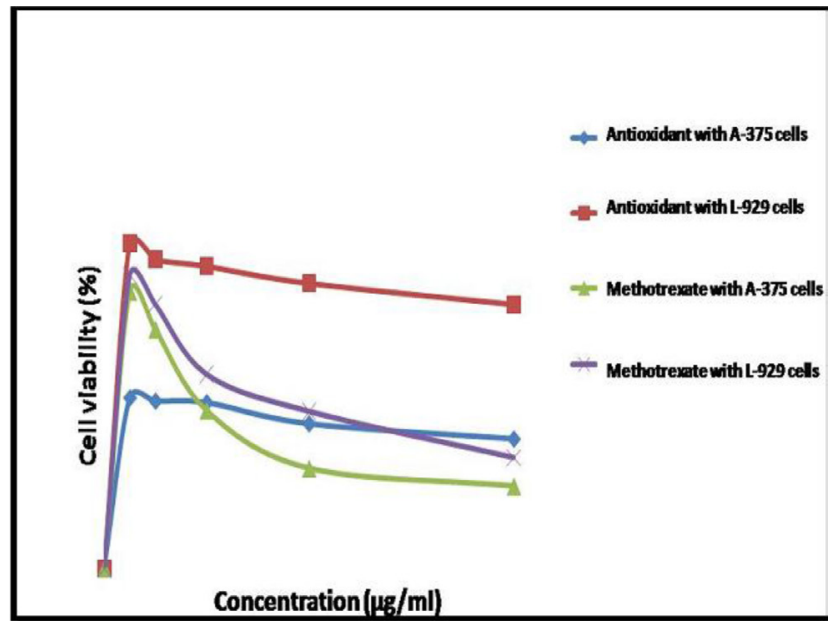

Figure 4: Effect of AMM and methotrexate on in vitro proliferation assay in normal mouse fibroblast cells and melanoma cells.

proliferation in A-375 human malignant melanoma cells even at a lower concentration.

As stated above radiation and chemotherapeutic agents used to kill cancerous cells, produce a toxic effect on normal tissues and organs due to the increased oxidative stress in the patients. ${ }^{1-4}$ In present study, supplementation of AMM to the cancer patients receiving radiotherapy or chemotherapy drastically depleted oxidative stress markers such as MDA and nitric oxide by $16-20 \%$ and $25-41 \%$, respectively. These results indicate that AMM protects the patients from oxidative stress-induced by radiation and chemotherapeutic agents.

The decreased level of oxidative and nitrative stress in the patients treated with AMM during radiotherapy or chemotherapy may be due to the restoration of antioxidant status in these patients. This is evident by 24 to $88 \%$ increased levels of serum total antioxidant in the cancer patients.

Supplementation of AMM to the cancer patients receiving radiotherapy or chemotherapy also improved the endogenous antioxidant system in them. This 
finding well supported by $18-20 \%$ of increased concentration of SOD in radiotherapy or chemotherapy underwent patients and $26.46 \%$ glutathione peroxidase concentration in radiotherapy undergone patients.

In addition to endogenous antioxidant system supplementation of AMM to the cancer patients also restored the levels of exogenous antioxidants in them. Findings of the present study showed that there is a substantially increased levels of Vitamin C and Vitamin E in cancer patients.

The increased levels of endogenous and exogenous antioxidant may protect against radiotherapy or chemotherapy-induced oxidative stress especially in patients having impaired capacity to deal with an oxidative insult. ${ }^{4}$

Literature survey reveals that cancer therapy depletes essential trace element in patients especially selenium and zinc. ${ }^{10}$ The present study is in agreement with this finding as it is evident by decreased concentration of selenium and zinc in radiotherapy or chemotherapy underwent patients. On the other hand, increased concentration of copper is associated with various cancers, the present study data supports this as increased concentration of serum copper was found in the cancer patients. ${ }^{7}$ Interestingly, the outcome of trace elements analysis showed that supplementation of AMM to cancer patients increased the concentration of selenium and zinc by $27-30 \%$ and $7-13 \%$, respectively. On the other hand supplementation of AMM to cancer patients decreased the elevated copper concentration by $5-8 \%$.

As mentioned above, radiation and some chemotherapeutic agents used in cancer treatment generate ROS and a high ROS level diminishes cellular antioxidant capacity and cause cellular damage and necrosis of malignant cells. So a concern has logically developed as to whether exogenous antioxidant compounds taken concurrently during chemotherapy could reduce the beneficial effect of chemotherapy on malignant cells. ${ }^{4-7}$ Several clinical trials have produced conflicting results regarding the benefit of antioxidants in cancer therapy thus questioning the incorporation of these substances in standard treatment regimens. ${ }^{4,5}$ On the contrary literature survey of recent review articles for exploring the armoury of obscurity on concurrent use of antioxidant during chemotherapy revelled that antioxidant does not interfere with chemotherapy, they enhance the cytotoxic effect of chemotherapy, they protect normal tissue and increases patient survival and therapeutic response. ${ }^{4}$

In the present study data also wells support the above findings. The in vitro proliferation assay data suggests that AMM have no cytotoxic effect on normal mouse fibroblast cells as there is no decrease in the proliferation in normal mouse fibroblast cells. But AMM imparts suppression of cell proliferation in human malignant melanoma cells even at a lower concentration.

\section{CONCLUSION}

In conclusion, present study data demonstrated that use of antioxidants with multivitamin and mineral supplementation during cancer therapy was found to be beneficial as they minimize the burden of free reactive radicals and restores the endogenous and exogenous antioxidants and essential trace element levels towards normal. There appears enough scope for further studies with a larger population and selective agents in support of supportive therapy in this area.

\section{ACKNOWLEDGEMENT}

Authors thank the management and staff of Shri Siddheshwar Cancer Hospital and Research Centre, Solapur, Maharashtra, India for allowing us to conduct this work.

\section{CONFLICT OF INTEREST}

The authors declare no conflict of interest.

\section{ABBREVIATIONS}

AMM: Antioxidant with multivitamin and minerals; DNA: Deoxyribonucleic acid; GPx: Glutathione peroxidise; MDA: Malondialdehyde; RNA: Ribonucleic acid; ROS: Reactive Oxygen Species; SOD: Superoxide dismutase.

\section{REFERENCES}

1. Kruk J, Hassan Y, Aboul-Enein, Kładna A, Bowser EJ. Oxidative stress in biological systems and its relation with pathophysiological functions: The effect of physical activity on cellular redox homeostasis. Free Radical Research. 2019;53(5):497-521.

2. Dhadde SB, Nagakannan P, Roopesh M, Anand K, Thippeswamy BS, Veerapur VP, et al. Effect of embelin against 3-nitropropionic acid-induced Huntington's disease in rats. Biomed Pharmacother. 2016;77:52-8.

3. Gaweł S, Wardas M, Niedworok E, Wardas P. Malondialdehyde (MDA) as a lipid peroxidation marker. Wiad Lek. 2004;57(9-10):453-55.

4. Singh K, Bhori M, Kasu YA, Bhat G, Marar T. Antioxidants as precision weapons in war against cancer chemotherapy induced toxicity - Exploring the armoury of obscurity. Saudi Pharm J. 2018;26(2):177-90.

5. Prasad S, Gupta SC, Tyagi AK. Reactive oxygen species (ROS) and cancer: Role of antioxidative nutraceuticals. Cancer Lett. 2017;387:95-105.

6. Oliveira AM, Mata F, Carvalho R, Oliveira MV, Alencar B, Carvalho AA, et al. Ascorbic acid in the prevention and treatment of cancer. Rev Assoc Med Bras. 2016;62(7):680-6.

7. Okunade KS, Dawodu OO, Salako O, Osanyin GE, Okunowo AA, Anorlu RI. Comparative analysis of serum trace element levels in women with invasive cervical cancer in Lagos, Nigeria. Pan Afr Med J. 2018;31:1-7. 
Pirincci N, Gecit I, Gunes M, Kaba M, Tanik S, Yuksel MB et al. Levels of serum trace elements in renal cell carcinoma cases. Asian Pac J Cancer Prev. 2013;14(1):499-502.

9. Kaba M, Pirinççi N, Yüksel MB, Geçit I, Günes M, Demir M, et al. Serum levels of trace elements in patients with testicular cancers. Int Braz J Urol. 2015;41(6):1101-07.

10. Hasan A. Effect of Chemotherapy on $\mathrm{Zn}, \mathrm{Fe}, \mathrm{Mg}, \mathrm{Pb}, \mathrm{Ca}$ and Se in the Serum. Mod Chem Appli. 2017;5(212):1-5.

11. Satoh. K. Serum lipid peroxide in cerebrovascular disorders determined by a new colorimetric method. Clin Chim Acta. 1978;90(1):37-43.

12. Cortas NK,Wakid NW. Determination of inorganic nitrate in serum and urine by a kinetic cadmium-reduction method. Clin Chem. 1990;36(8):1440-3.

13. Pisoschi AM, Negulescu GP. Methods for total antioxidant activity determination: A review. Biochem Anal Biochem. 2011;1(1):1-10.
14. Randox Ltd. Determination of superoxide dismutase and Glutathione peroxide. Tech Bull Free Radical. 1994;12-14.

15. Frank B. Vitamin E. In clinical vitaminology methods and interpretation, Interscience publishers, New York. 1968;169-76.

16. Goyal MM, Kalwar AK, Vyas RK, Bhati A. A study of serum zinc, selenium and copper levels in carcinoma of esophagus patients. Indian J Clin Biochem. 2006;21(1):208-10.

17. Das K, Samanta L, Chainy GBN. A modified spectrophotometric assay for superoxide dismutase using nitrite formation by superoxide radicals. Indian J Biochem Biophy. 2000;37:201-04.

18. Zloch Z, Cerven J, Ginter E. Radiochemical evaluation of the 2,4-dinitrophenylhydrazine method for determination of Vitamin C. Anal Biochem. 1971;43(1):99-106

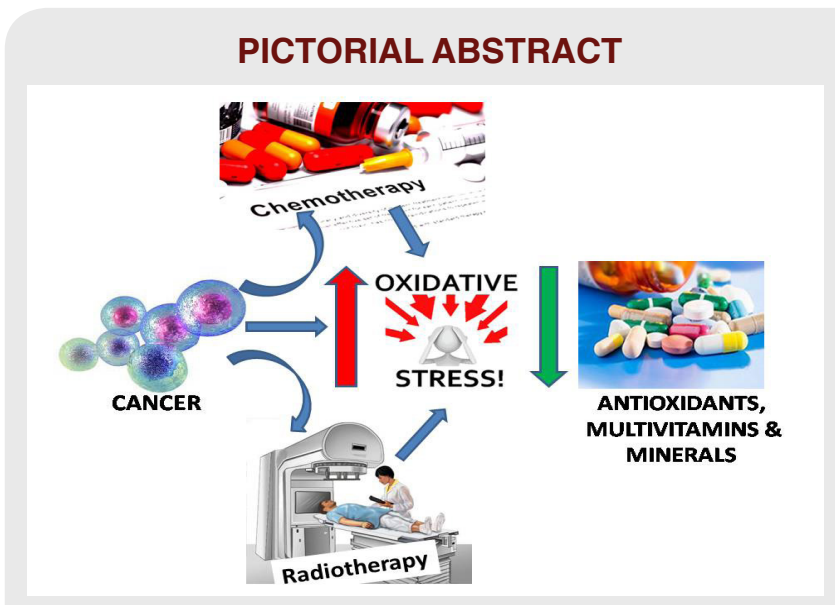

\section{SUMMARY}

In this study, cancer patients were supplemented for 30 days with antioxidants with multivitamin and mineral (AMM) along with radiotherapy and chemotherapy. Supplementation of AMM during cancer therapy minimized the burden of free reactive radicals and restored the endogenous and exogenous antioxidant levels and essential trace elements. In addition, AMM has no cytotoxic effect on L-929 normal mouse fibroblast cell line. But AMM imparts suppression of cell proliferation in A-375 human malignant melanoma cell line. Supplementation of antioxidants with multivitamin and mineral during cancer therapy was found to be beneficial.

\section{About Authors}

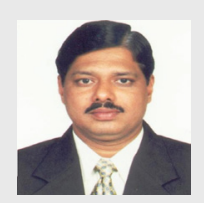

Dr. Harinath Nivrutti More, Professor and Principal, Bharati Vidyapeeth's College of Pharmacy, Kolhapur, completed B. Pharm, M. Pharm and Ph.D. from Pune Univeristy, Pune. He has more than 33 years of Teaching, Research and Administrative experience. Guided 8 Ph.D. and more than 60 M.Pharm students. He supervised 15 funded major and minor research projects worth more than 75 lakh rupees and 14 patents on pharmaceutical formulations are filed under his guidance. Authored 9 books and published 145 research papers in National and International journals. Has been a resource person for many FDPs, Workshops, QIPs and is a reviewer for reputed journals. Dr. More is serving various bodies of different universities.

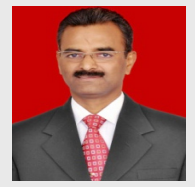

Prof. Ravikant Yashwantrao Patil, Principal, D S T S Mandal's College of Pharmacy, Solapur, completed B. Pharm from Govt. College of Pharmacy, Bangalore and M. Pharm (Pharmacology) from KLES's College of Pharmacy, Belgaum. He has 35 years of Teaching, Research and Administrative experience of which as Principal since 1996. Served as Chairman for Lapses Committee, Syllabus Committee, BOS and as Member Management Council, Senate, Academic Council, BUTR, Faculties of Medicine and Engineering, RRC, Skill Development Centre and as RUSA Coordinator in Solapur University and Shivaji University. Prof. Patil has served Solapur University for Two years as Director, Board of Colleges and University Development.

Cite this article: Patil RY, More HN. Antioxidants with Multivitamin and Mineral Supplement Attenuates Chemotherapy or Radiotherapy-induced Oxidative Stress in Cancer Patients. Indian J of Pharmaceutical Education and Research. 2020;54(2):484-90. 